\title{
Invited Response on: "Autologous Fat Grafting with Percutaneous Fasciotomy and Reduction of the Nipple-Areolar Complex for the Correction of Tuberous Breast Deformity in Teenagers"
}

\author{
Nina S. Naidu ${ }^{1}{ }_{(\mathbb{C}}$
}

Received: 23 January 2021 / Accepted: 24 January 2021 / Published online: 8 February 2021

(C) Springer Science+Business Media, LLC, part of Springer Nature and International Society of Aesthetic Plastic Surgery 2021

Level of Evidence $V$ This journal requires that authors assign a level of evidence to each article. For a full description of these Evidence-Based Medicine ratings, please refer to the Table of Contents or the online Instructions to Authors www.springer.com/00266.

We thank the authors for their gracious comments about our paper and results [1]. We agree that the incidence of tuberous breast deformity appears to be increasing worldwide [2], although the etiology for this increase is unclear. This author notes anecdotally that the cases presenting to her clinic are more numerous, but less severe, than they were a decade ago.

We are familiar with the authors' technique of using 18 -gauge needles and the Seldinger technique to release scar tissue and allow deposition of fat grafts [3]. Our use of a 2-mm Toledo cannula with a sharp v-shaped tip is essentially a modification of this concept. Because this instrument is longer than an 18-gauge needle, we find that it allows more efficient release of the elevated inframammary fold and constricted tissue, while still permitting good control.

Fat grafting plays an increasingly important role in plastic surgery, and particularly in aesthetic breast surgery. Tuberous breast deformity patients frequently request fat grafting rather than implant placement, which is reasonable given their overwhelming desire to correct shape rather than add volume. Indeed, our only limitation on the use of lysis and fat grafting is the donor site, which is not always

Nina S. Naidu

drnaidu@naiduplasticsurgery.com

1021 Park Avenue, New York, NY 10028, USA well developed in the young women presenting for correction.

We once again would like to thank the authors for their close attention to our article and their very kind comments.

\section{Compliance with Ethical Standards}

Conflicts of interest Nina S. Naidu, MD FACS is a shareholder of Ideal Implant, Inc. and is a consultant for Establishment Labs.

Human and Animal Rights This article does not contain any studies with human participants or animals performed by any of the authors.

Informed Consent For this type of study, informed consent is not required.

\section{References}

1. Battistini A, Lisa A, Maione L, Klinger M, Klinger F. Comment on: "Autologous fat grafting with percutaneous fasciotomy and reduction of the nipple-areolar complex for the correction of tuberous breast deformity in teenagers. Aesthetic Plastic Surgery. In press.

2. Klinger M, Caviggioli F, Giannasi S et al (2016) The prevalence of tuberous/constricted breast deformity in population and in breast augmentation and reduction mammaplasty patients. Aesth Plast Surg 40(4):492-496

3. Klinger M, Klinger F, Caviggioli F, Maione L, Catania B, Veronesi A, Giannasi S, Bandi V, Giaccone M, Siliprandi M, Barbera F, Battistini A, Lisa A, Vinci V (2020) Fat grafting for treatment of facial scars. Clin Plast Surg 47(1):131-138

Publisher's Note Springer Nature remains neutral with regard to jurisdictional claims in published maps and institutional affiliations. 